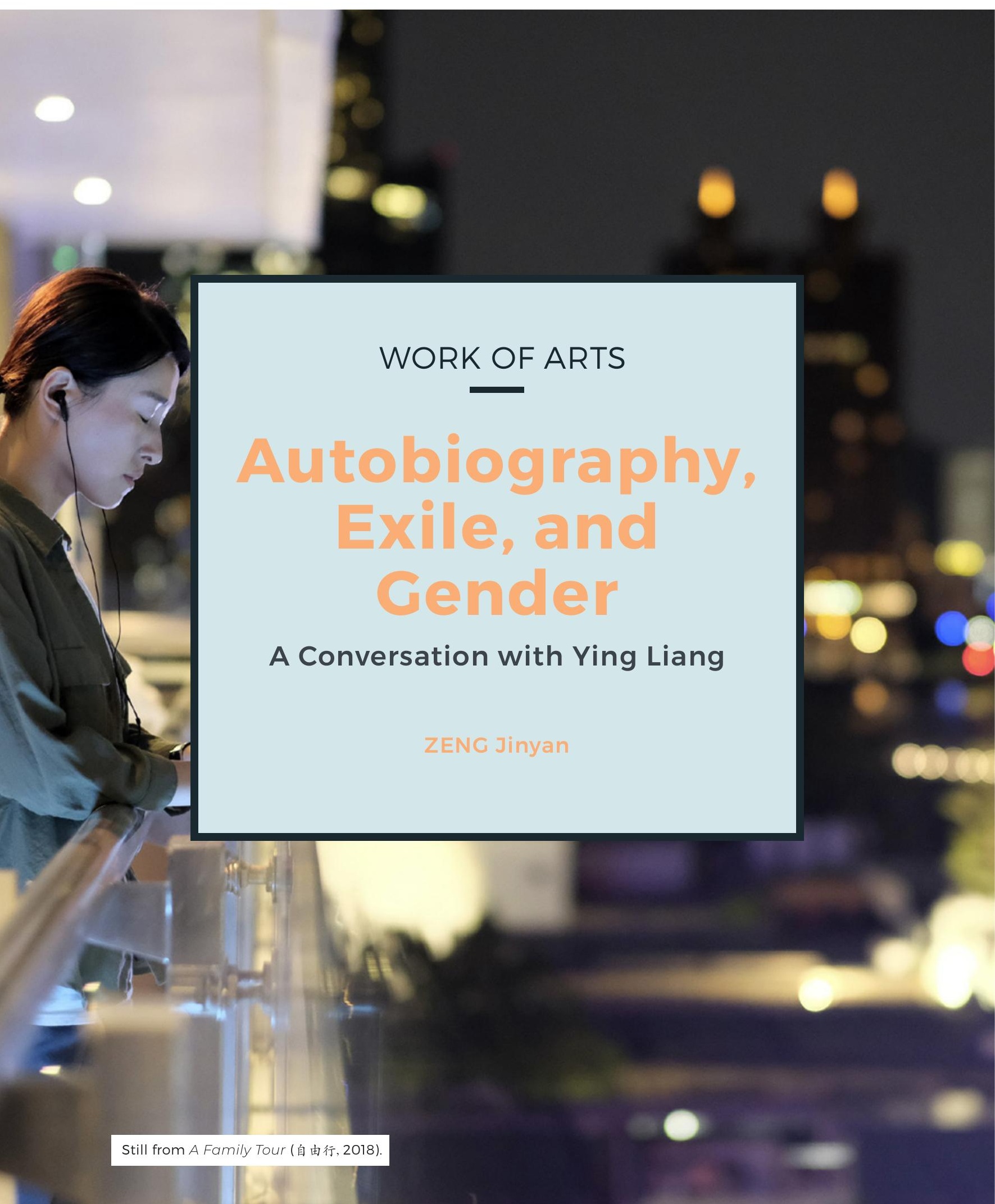




\section{Autobiography, Exile, and Gender A Conversation with Ying Liang}

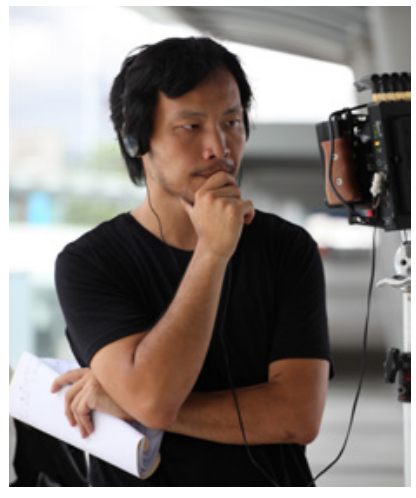

Ying Liang.
Ying Liang is an independent filmmaker, whose work encompasses film curation, teaching, and commentary. His well-known feature films include Taking Father Home ( 背鸭子的男孩 2005), When Night Falls (我还有话要说 2012), as well as the short movies Condolences (慰问 2009), A Sunny Day (九月二十八日·晴 2016). Ying's works have won numerous international awards; When Night Falls earned him the best director award and Nai An won the best actress award at the Locarno Film Festival. In 2018, he released his autobiographical feature film A Family Tour (自由行), which debuted at the International Competition section of the Locarno Film Festival, was screened at the fifty-sixth New York Film Festival, and was the closing film at the eighteenth Kaohsiung Film Festival.

The film tells the story of Yang Shu (played by the actress Gong Zhe), who is punished by the Chinese government for making a movie and has to go into exile in Hong Kong, with no chance of returning to China. Her mother (played in the movie by Nai An) remains in Sichuan, where she suffers a relapse of stomach cancer and needs to undergo an operation. As a result, she desperately wants to meet her daughter and grandson, whom she only knows from communication over the Internet. An opportunity arises for a reunion at a film festival in Taiwan, which Yang Shu plans to attend with her husband (played by Peter Teo) and their son. Yang's mother books a tour to the island, but cannot leave the tour group to travel on her own. As a makeshift solution, Yang's husband books the same hotels as the mother, and they follow the itinerary of her tour group, allowing the family to reunite at hotels and various scenic spots in Taiwan. 
Ying Liang: This is quite a personal story. Much of the film draws on my own experiences, and it is a 100-percent reflection of my feelings and emotions. But of course, to narrate a story that can be widely disseminated, it is essential to adapt certain elements. I don't really expect that after watching the film the audience will assume that the person in the movie is me, or that what happened in the film is a perfect account of my own experiences. I believe that stories need to reflect true feelings and emotions, rather than perfectly reproduce what happened in real life. This kind of latitude allows filmmakers to adjust their stories, and also provides an opportunity for personal reflection. This provides a means of achieving deeper self-understanding-making this film provided the opportunity for me to reconsider my own experiences and my relationships with my parents, among other things.

Actually, over the past six years I have been blessed with numerous friends in Hong Kong, who have both witnessed and facilitated important changes in my life. It was interesting to have the film screened in Hong Kong. I feel that Hong Kong locals and audiences who have close ties with city are very responsive to the characters in the film, as they have found themselves involved in similar situations. I feel quite glad about this because I was not expecting such responsiveness and commonality when I was writing the film.

One of the original motivations for writing A Family Tour was that I wanted to communicate with my child. He was born in Hong Kong, and was almost four years old when I was writing the film. I feel that Chinese people always face the problem of a lack of communication between generations, especially in families that have experienced traumas. These traumas are seldom mentioned because people feel frightened, think it is unsafe, and are afraid of destroying the relatively stable life that they have carved out for themselves. My family was also like this. I really longed for the possibility of openly communicating with my child. When I was writing the script, I told him: 'I'm writing a story about us going to Taiwan to meet your grandma. This story is a gift for you, and I am writing it now.' He was a bit more than three years old at that time. He sat on my lap and watched me typing. Later, when we were ready to shoot the film, Gong Zhe-the actress playing Yang Shu-came to Hong Kong, and hung out a lot with my son; they became friends. During shooting, my son would often come to the filming location as well. In fact, he had many impressions and feelings, and understood the effort I was making. This is my original motivation for making the film. At the film festival, he watched the film from beginning to end. He was very little, only five years old and the fact that he concentrated on watching the film was fascinating and meaningful to me. 
YL: As I mentioned, I don't want the audience to think that the protagonist is a perfect representation of me, since this would have narrowed the appeal of the film. For people like me, who have been in exile, meeting family at a third location can be considered a kind of collective memory or collective experience. I was thinking this way when writing the film. I also spoke with friends who have had similar experiences to mine, and privately showed the film to friends with similar backgrounds. Their reaction was that it is our story rather than simply the story of an individual.

I also needed a certain distance to examine and refine the narratives in the film. In real life, when my own family reunification in Taiwan occurred, I was helping students with their script writing. My students needed me to help them solve all kinds of problems that they encountered in their writing. What is a story? How should the behaviour of characters be designed? How can a starting point or angle be chosen to help complete communication involving more people? Naturally, I used my upcoming journey as an illustration, and the students thought it would be great if it could be filmed. However, it was completely out of the question to film the whole journeyit would have been impossible to distinguish the identity of the person who was experiencing the event from the identity of a filmmaker, and thus impossible to accomplish an artistic work. Back then, I mainly treated my narrative as a teaching conversation, like communication between friends, hoping that my students could get some inspiration from it. I told my students that narrating stories like this would require them to think deeply about time and space, and to find a suitable perspective and method. I stopped short of taking any further action beyond my story telling.

These conversations with my students took place four years ago, when my child was about one year old. It was not until two years later, that I finally had some room to digest and look at my own family reunion with fresh eyes. Only at that moment did I start to consider turning the story into something that could be conveyed to more people. I was not very courageous then, but many of friends who heard me talking about this idea, especially some filmmakers in Taiwan where I planned to shoot the film, expressed their support, so I decided to have a go. But I knew it would be extremely hard. The crux of the issue was that when I started to write the script, I realised that because I was so close to the story, I couldn't make rational judgments about 
many aspects of the narrative, and couldn't use my identity as a creator to solve certain problems. There were many things that I didn't realise needed explaining, as the story was so personal.

In addition, the other two co-scriptwriters of the film were both female, and we became interested in the challenge of writing about mother-daughter relationships. My wife and I began writing the script, and when we were on the third or fourth draft my friend Wai Chan joined us. She is a bit older than me, and grew up in Hong Kong rather than mainland China. She is a novelist, and was a colleague of mine when I was teaching in Hong Kong. She provided me with numerous suggestions for the first few drafts of our script, which dealt huge blows to my ideas, making me both miserable and delighted. From her comments I gained new understandings of my relationship with my own mother and with China. I began to rethink my own problems. Finally, I said to Wai Chan: 'Only by formally inviting you to join us in writing the script can I have the chance to finish it with your help.' Since it was a sincere request, she agreed. In our new team, I was still responsible for most of the writing, but would send her every draft. She was like a lighthouse, standing beside me and clearly identifying all the problems in the script. She would then sit me down and provide me with some very critical comments. We wrote eleven or twelve drafts in total. It was not until the ninth or tenth draft that she started to do some actual writing. She refined some details of the script and adjusted the order and structure of some scenes, among other things. This was how our writing process unfolded.

When I first talked to Wai Chan, the protagonist was a male director, making it impossible to distinguish the story from my own life. The character of his wife was also indistinguishable from my wife, who accompanied me in exile from China to Hong Kong. In rejecting this idea, Wai Chan said: 'First, the concept of exile does not really come into existence if everyone in the family is in exile, because there is no contrast of identity and no difference in their rights and difficulties-a certain differentiation must exist. Second, the status of women will be very low in the film if the director is a male.' Originally, the role of the director's wife was someone who was always ready to help, walking around in the background, quietly arranging the itinerary, and taking care of the child. I considered this and her other suggestions, and ultimately accepted them all. 
YL: In the initial draft of our script, the biggest problem was that I wrote a very happy, warm, and emotional scene for the first meeting of the grandma and her grandson. As a filmmaker, I definitely would not have liked this style of writing. But I didn't realise the problem at that time because writing the script helped me to accomplish something unachievable. In real life, I have not seen my parents for six years. In our own journey, we travelled to Taiwan to meet my wife's family. So I envisaged the scene in which my child met my mother to be cosy and joyful. Wai Chan said to me: 'Such a scene cannot happen. Children actually feel scared when they first meet the elderly because their smell, which foreshadows death, is particularly hard for children to accept.' Wai Chan clearly pointed out the issues for me. Only at that moment did I realise that I had been avoiding filling this particular film with sorrow and psychological scars, but this was actually a really bad practice. I needed Wai Chan's way of looking at things. As a Hong Kongese-rather than a mainlander-she had a perspective of distance, through which I found a kind of truth.

Wai Chan's insight can be clearly seen in following scene: on the first night, the team leader of the Chinese tour group came to the hotel room to announce requirements about the upcoming itinerary and rules for independent travellers joining the tour. When I started to write this scene, I portrayed the protagonist Yang Shu as being very unhappy, mainly with the team leader. Wai Chan said to me: 'This is not right. Actually, she is most unhappy with her mother, because the way her mother handles everything is exactly the typical mainland Chinese behaviour that she hates most, and the China that she loathes most is fully reflected in her mother.' At that moment, I was deeply hurt by Wai Chan's sharp remarks, for what she said was indeed my situation, but I just couldn't confront the reality.

Another example of her insight was on display in her edits to the first draft of our script. The opening scene was on a flight. Everyone in the family was on a plane to Taiwan, and the flight attendants asked if they needed incoming passenger cards. Wai Chan said to me: 'This is such a complicated a journey and starting with this scene will not allow the audience to understand the complexity. One main character is a child, who was born in Hong Kong; he needs to do an online application for his visa to Taiwan. Another is the elderly mother, who lives in China but wants to travel to Taiwan; she must stay with the tour group because her passport is held by the tour guide. The third main character is Yang Shu with a somewhat complicated identity: she is the child's mother and since she is in exile in Hong Kong she has to go through a special procedure to obtain a Taiwanese visa. The fourth main character is the young Hong Kongese dad who frequently travels back and forth to China 
to hold exhibitions. You need to reserve sufficient time for unpacking all these complexities.' These suggestions for script revisions were very sensible, technical, and close to how I really felt, but just hadn't realised at that time. I relied very much on Wai Chan's advice and guidance.

I put my thoughts and feelings about Hong Kong into the character of the Yang Shu's Hong Kongese husband. The husband is a low-profile yet indispensable character that went through further development when we were selecting the actor. In the film, the husband was actually very nice, in a kind of radiantly perfect way. If we had chosen an actor who was always outgoing and optimistic, this would have been boring. I then started to think: which actor can play the role, among those whom I know of and whose films I have watched? Our final choice was the actor who usually takes a gangster role in independent films in Malaysia. He makes independent rock music and his songs are all a bit dark. This edginess served to complement the character.

I have been in exile since I left China. This experience has provided me with a different perspective, allowing me to see and experience different cultures and places. In my daily life, comparisons abound between my past experiences in China, which are still in my memory, my interactions with Chinese friends, my life in Hong Kong, and my trips to Taiwan. When writing the film, I drew on these comparisons, experiences, and observations. The film was also the product of a team effort, rather than my own work alone-everyone on the team had freedom to innovate and put their own feelings and understandings into the story and characters.

\begin{abstract}
ZJY: Around 2012, independent directors who faced political repression due to their works and thus relocated to Hong Kong-including you. Huang Wenhai, and myself, together with two young scholars in Hong Kong (Tit Leung Cheung and Li Tiecheng)established the Chinese Independent Documentary Lab and started to organise film curation, discussions, research, and filmmaking. Now it is 2019, and we have decided to disband our Lab. The Chinese Documentary Film Festival founded by Hong Kongese director Tammy Cheung will also be renamed as the Hong Kong International Documentary Film Festival. You believe that these changes epitomise and herald a wider trend. Why do you think so? On a side note, I noticed that many small objects in your latest film were related to independent film festivals, and I feel that it is almost an elegy for Chinese independent films. I am wondering how the audience outside the world of independent films will perceive this.
\end{abstract}

YL: In A Family Tour, independent filmmaking is like an invisible storyline; people who know the scene will immediately get it. But it is not the main theme of the film; it is only something complementary or something hidden behind the story, which pertains to the Chinese independent film movement. A crucial 


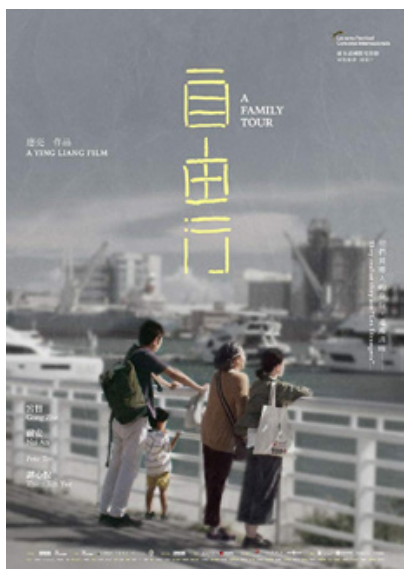

A Family Tour (自由行, 2018). turning point for this movement happened at the beginning of the century, when people started to get together to watch independent films and some exhibitions emerged. These gatherings were either semi-official or semi-underground, and faced numerous uncertainties; it was very common that the screenings could not finish or had no choice but to self-censor. This activity reached a peak around 2008, when high-quality works abounded. I also participated in film curation at that time, and organised local film festivals in Chongqing. Back then, as many as 300 films were received each year, including shorts and experimental films, with more than 100 being screened at the festival. These figures were shocking in China. Because of all the constraints with regard to promotion, the size of the audience was not very large: maybe around a couple of thousand over a week. At that time, four to five cities in China, or even more, had similar collective screening events and had established definite audiences. There were ongoing conversations and resonances between directors, audiences, and commentators. Back then, the creative and discursive environments were both relatively positive. Everyone had the same feeling that it seemed possible to do anything. All kinds of conversations were happening including conversations with officials; it was a honeymoon and utopian feeling.

The situation began to deteriorate around 2010, and exhibitions of independent films completely came to an end in 2012. Some large-scale independent film festivals and film exhibitions with nearly a decade of history were formally and forcibly closed down by the government. Previously, the interference in independent film festivals was comparatively mild-certain measures were usually adopted to force film festivals either to go underground, where they could continue their screening, or to change their names and locations. In 2012, there was absolutely no chance for independent film festivals to survive even if they took these precautions.

In this context, some filmmakers emigrated, but still go back to China occasionally to make their movies. Some filmmakers are in exile, holding film exhibitions or other activities abroad. Others remain in China and are now doing some small-scale screenings. Having no way to concentrate their screenings at one time or place, they can only do piecemeal screenings on the weekends and at irregular intervals. Film projectors are facing increasingly stringent self-censorship, and the scope of discussion is also getting narrower. All these changes have then led to a situation in which films can no longer be screened in their entirety as they could in the past.

Chinese independent films used to play quite a leading role. Among the numerous examples is an independent film named Petition (上访 2008) by director Zhao Liang. After ten years of 
shooting, the film finally debuted in 2008. Back then, only a few people were actually watching independent films, and many felt that the experience of petitioners was too far away from their life, so it was just a story. Nowadays, however, anyone is likely to become a petitioner at any moment due to, for example, what is happening to their children in the kindergarten. Almost anything can turn a commoner into a petitioner. Independent films took the lead. However, their demise, from my perspective, was also inevitable. I feel that Chinese independent films have already become a thing of the past.

During the preparation for shooting A Family Tour, I collected some clothes, bags, and other things from independent film festivals. The protagonist Yang Shu is someone who has attended many exhibitions of independent films over a long period. I wrote biographies for the characters. Both the actors and I knew well what kind of film exhibitions that Yang Shu had attended, how the exhibitions had changed, and what impacts these changes had on her own work. The character is active in exhibitions of independent films; her Hong Kongese husband is also a film curator who travels between different places. Such artistic activities and backgrounds of the characters mean that everything they possess is closely related to the recent history of the independent film movement. As with the preceding poetry and independent music movements, the independent film movement has already become a feature of the past. In the film, this past was in exile, or, to put it another way, objects related to the past were presented as if they were relics of another time. This is why independent film constitutes an invisible storyline of $A$ Family Tour, which narrates the gradual demise of China's independent film movement and intends to memorialise it. It is also a nod to my friends involved in the independent film movement.

\section{ZJY: In China, independent filmmakers are usually marginalised and find it hard to get in touch with the audience, readers, or commentators. Does this situation constitute another form of exile? Your short film A Sunny Day, which recounts the Umbrella Movement, was released in 2016, and you were described as 'having sworn allegiance' to Hong Kong, and even as having become a Hong Kongese. In A Family Tour, the protagonist Yang Shu replied that she was a stranger after being repeatedly asked if she perceived herself as a Hong Kongese. What did you want to convey to the audience with this statement?}

YL: Po Chung Chow, a political science professor at the Chinese University of Hong Kong, once wrote on Facebook: 'If freedom is a very important value in our daily life, how will you then face the loss of freedom in your surroundings?' When such loss makes your surroundings increasingly strange to you, you have actually become a stranger, an unknown person. 
At this moment, you may have to make some choices. Should you simply adapt to the new environment, hoping that all the confusion, suffering, or loneliness will disappear? Or should you choose to do something else, such as leave? Or should you stay and continue to fight against your new surroundings, being ready to bear the ramifications? The last option may put you in a situation where you feel even lonelier and even fewer people can understand you.

During our discussion about the last version of the script, Wai Chan asked me: 'What does Yang Shu actually want?' I was dumbstruck. Although I had spent much time creating and writing about the character, I could not actually offer a reasonable explanation of what she actually wanted. Wai Chan suggested that I read Wang Dan's book My Identity as a Stranger Is Becoming Clearer (我异乡人的身份逐渐清晰 2003). So I did, and later asked the actress who played Yang Shu to read it as well. I feel that it is a great book that touches on issues of identity that are important to the character of Yang Shu at her stage of life. She is a female, mother, and filmmaker, but of course, her identity is not this simple.

Exile has always existed and continues to exist, including exile pertaining to literature, poetry, music, and independent films. Even some contemporary mainstream filmmakers used to be in exile, but because many of them have never mentioned or publicly discussed this, their experiences have gradually faded into the past and have been ignored. For example, for a long time I didn't know that in the aftermath of the June Fourth Incident, many mainstream filmmakers actually went into exile and stayed in the United States or other countries for a while because they had expressed support for students or held viewpoints that differed from the official stance. Back then, these filmmakers, including some who are now very active in China's film industry, all made their choice between going into exile or staying put. The discursive space for these topics is somewhat obscure and invisible. I don't have any statistics, but I feel that exile is part of the human experience. When it happens in our sphere, we will feel that it is getting increasingly common. Since political situations have turned acute and have been changing rapidly over the past few years, more and more people around me have exited. It does seem that the number of independent filmmakers who left or were exiled from China has become larger. Nonetheless, I don't think these filmmakers are separate from those mentioned before; they actually all belong to the same generation. 